JKM (Jurnal Kebidanan Malahayati),Vol 7,No.2.April 2021,

ISSN (Print) 2476-8944 ISSN (Online) 2579-762X, Hal 319-323

\title{
PERBANDINGAN PENGARUH TEKNIK ENDORPHINE MASSAGE DENGAN KOMPRES HANGAT DALAM MENURUNKAN SKALA DISMENORE
}

\author{
Hani Septiani ${ }^{1}$, Sri Wulan Ratna Dewi ${ }^{2}$ \\ STIKes Muhammadiyah Ciamis \\ *Korespondensi email sriwulanratnadewi@gmail.com
}

\section{ABSTRACT COMPARISON OF THE EFFECT OF ENDORPHINE MASSAGE ENGINEERING WITH WARM COMPRESS IN REDUCING DISMENORE SCALE}

Background dysmenorrhea or menstrual pain is the symptom most often complained of by women of reproductive age. Pain or pain that is cyclic along with menstruation is often felt like cramps in the stomach and can be accompanied by pain radiating to the back, with nausea and vomiting, headaches or diarrhea. Menstrual pain can last from a few hours to a day. Sometimes, these symptoms can last more than 1 day but rarely exceed 72 hours. Accompanying systemic symptoms include nausea, diarrhea, headache and emotional changes. In general, the management of menstrual pain is divided into two categories, namely pharmacologically and nonpharmacologically. non-pharmacological methods are a safer alternative and have no side effects. Nonpharmacological management is safer to use because it does not cause side effects of drugs.

Purpose to analyse the comparison of the decrease in dysmenorrhea by applying endorphin massage and warm compress technique.

Method This study used quasi experiment in which applied pretest-posttest control group design approach with total samples of 78. Respondent sampling was conducted by using purposive sampling. Menstrual pain variables were measured with Numerical Rating Scale. The analysis process used Mann Whitney and Kruskal Wallis test.

Results of the study show that there were a significant differences between endorphin massage and warm compress technique on the $1^{\text {st }}, 2^{\text {nd }}$, and $3^{\text {rd }}$ days of menstruation after being given a treatment for 15 minutes with the $p$-value of $0.000<\alpha=0.05$.

Conclusion Endorphin massage technique is faster in reducing the scale of dysmenorrhea than warm compress. This technique is safe, easy, free of charge, has no side effect, and can be done with the closest person or by yourself.

Suggestion The results of the research can become a study material or reference for other researchers in subsequent studies and become a learning resource for readers, especially about endorphin massage as a nonpharmacological therapy to treat dysmenorrhea.

Keywords: endorphin massage, menstrual pain

\section{ABSTRAK}

Latar Belakang dismenore atau nyeri haid merupakan gejala yang paling sering dikeluhkan oleh wanita usia reproduktif. Nyeri atau rasa sakit yang siklik bersamaan dengan menstruasi ini sering dirasakan seperti rasa kram pada perut dan dapat disertai dengan rasa sakit yang menjalar ke punggung, dengan rasa mual dan muntah, sakit kepala ataupun diare. Nyeri haid dapat berlangsung dalam beberapa jam sampai 1 hari. Kadangkadang, gejala tersebut dapat lebih dari 1 hari tapi jarang melebihi 72 jam. Gejala sistemik yang menyertai berupa mual, diare, sakit kepala dan perubahan emosional. Secara umum penanganan nyeri haid terbagi dalam dua kategori yaitu secara farmakologi dan non farmakologi. metode non farmakologi menjadi alternatif yang lebih aman dan tidak ada efek samping. Manajemen nonfarmakologi lebih aman digunakan karena tidak menimbulkan efek samping obat-obatan.

Tujuan penelitian ini menganalisis perbandingan penurunan dismenore menggunakan teknik endorphine massage dibandingkan dengan kompres hangat.

Metode penelitian menggunakan quasi eksperimen dengan pendekatan pretest-posttest control grup design dengan jumlah sampel 78. Pengambilan sampel responden pada penelitian ini dilakukan dengan menggunakan purposive sampling. Variabel nyeri haid atau dismenore diukur dengan menggunakan Numerical Rating Scale(NRS). Analisis yang digunakan yaitu uji Mann Whitney. 
Hasil penelitian ini menunjukkan bahwa terdapat perbedaan yang signifikan antara teknik endophine massage dengan teknik kompres hangat pada hari ke 1,2 dan 3 menstruasi setelah diberikan treatmen selama 15 menit dengan hasil nilai $p$-value $0.000<\alpha=0,05$.

Kesimpulan Teknik endorphine massage lebih cepat menurunkan skala dismenore dibandingkan dengan teknik kompres hangat. Teknik ini aman, mudah, tidak membutuhkan biaya dan tidak memiliki efek samping juga bisa dilakukan dengan orang terdekat ataupun sendiri.

Saran Hasil penelitian dapat mejadi salah satu bahan kajian atau referensi untuk peneliti lain dalam penelitian-penelitian selanjutnya serta menjadi baham pembelajaran bagi para pembaca terutama tentang endorphin massage sebagai terapi non farmakologi untuk mengatasi dismenore.

Kata kunci : endorphine massage, nyeri haid

\section{PENDAHULUAN}

Dismenore merupakan salah satu gejala yang paling sering dikeluhkan oleh wanita usia reproduktif. Nyeri atau rasa sakit yang siklik bersamaan dengan datangnya menstruasi ini sering dirasakan seperti kram pada perut bagian bawah dan dapat disertai dengan rasa sakit yang menjalar ke bagian punggung, dengan rasa mual $d$ an muntah, sakit kepala ataupun diare. Derajat nyeri haid cukup bervariasi, mulai dari yang skala ringan sampai yang skala berat. Pada saat keadaan nyeri yang hebat dapat mengganggu aktivitas sehari-hari, sehingga memaksa penderita untuk beristirahat dan meninggalkan pekerjaannya. Hampir semua wanita mengalami rasa tidak enak pada perut bagian bawah saat menstruasi. Uterus atau rahim terdiri atas otot yang juga berkontraksi dan relaksasi. Umumnya, kontraksi otot uterus tidak dirasakan, namun kontraksi yang hebat dan sering menyebabkan aliran darah ke uterus terganggu sehingga timbul rasa nyeri. Nyeri haid dapat berlangsung atau dirasakan dalam beberapa jam sampai dengan 1 hari. Kadang-kadang, gejala tersebut dapat lebih dari 1 hari tapi jarang melebihi 72 jam. Gejala sistemik yang menyertai seperti adanya mual, diare, sakit kepala dan perubahan emosional. Secara umum penanganan dismenore terbagi dalam dua kategori yaitu secara farmakologi dan non farmakologi. Selama ini banyak wanita dan remaja memilih mengatasi masalah dismenore dengan cara farmakologi dengan mengkonsumsi obat anti nyeri (analgesik) golongan Non Steroid Anti Inflamasi Drug (NSAID) seperti ibuprofen dan asam mefenamat. Hal tersebut bisa membahayakan dikarenakan efek samping obat yang terkait dengan penggunaan NSAID, termasuk sakit perut, diare, mual, dan kerusakan hati atau ginjal setelah menghentikan pengobatan. Sehingga metode nonfarmakologi menjadi alternatif yang aman dan tidak ada efek samping. Manajemen nonfarmakologi aman digunakan karena tidak menimbulkan efek samping seperti obat-obatan atau farmakologi. (Priscilla V, Dwi dan Lili. 2012)

\section{METODOLOGI PENELITIAN}

Metode penelitian ini menggunakan rancangan Quasi Eksperimen dengan pendekatan pretest-posttest control grup design dengan jumlah sampel 78 mahsiswi yang dibagi menjadi dua kelompok. Penelitian ini di laksanakan pada bulan Agustus sampai dengan September 2018. Pengambilan sampel menggunakan cara purposive sampling. Variabel independen, yaitu teknik endorphin massage serta kompres hangat yang dilakukan pada hari pertama haid sampai hari ke tiga. Variabel dependen, yaitu skala nyeri haid. Responden yang mengalami dismenore pada hari pertama menghubungi peneliti dan mengisi lembar Numeric Rating Scale untuk mengetahui skala nyeri dari masing-masing responden(pre-tes), dan di lakukan penilaian (post-tes) skala nyeri setiap 5 menit, sampai 5 menit ketiga jadi total 15 menit dan diulang pada hari ke 2 dan 3 . Sedangkan kelompok kompres hangat untuk responden menghubungi peneliti pada hari pertama haid yang mengalami dismenore. Kompres hangat dilakukan menggunakan buli-buli panas yang diselimuti kain selama 15 menit di atas simfisis. Pada saat dilakukan kompres hangat, lakukan penilaian (pre dan post tes) skala nyeri setiap 5 menit sampai 5 menit ketiga jadi total 15 menit, responden melingkari angka pada kuesioner yang telah diberikan yaitu Numeric rating scale dan diulang pada hari ke 2 dan 3. Penelitian ini berlangsung 1 bulan yaitu pada bulan Agustus - September 2018 dan sudah lolos uji etik STIKes Dharma Husada Bandung/ethical clearance dengan no 051/SDHB/Sket/PSKBS2/IX/2018.

\section{HASIL DAN PEMBAHASAN}

Penelitian ini dilakukan terhadap 78 orang responden dimana masing-masing kelompok berjumlah 39 orang responden dan selama penelitian tidak ada responden yang mengalami droup out. 


\section{JKM (Jurnal Kebidanan Malahayati),Vol 7,No.2.April 2021, \\ ISSN (Print) 2476-8944 ISSN (Online) 2579-762X, Hal 319-323}

Tabel 1.

Perbedaan Rata-Rata Skala Dismenore pada Kelompok Teknik Endorphine Massage Dengan Kelompok Teknik Kompres Hangat

\begin{tabular}{|c|c|c|c|c|c|}
\hline \multirow[t]{2}{*}{ Uraian } & \multicolumn{2}{|c|}{$\begin{array}{c}\text { Kelompok Teknik } \\
\text { Endorphine Massage }\end{array}$} & \multicolumn{2}{|c|}{$\begin{array}{l}\text { Kelompok Teknik } \\
\text { Kompres Hangat }\end{array}$} & \multirow[t]{2}{*}{ Nilai $p$} \\
\hline & & Mean & & Mean & \\
\hline \multicolumn{6}{|l|}{ Hari Ke-1 } \\
\hline Sebelum tes & 6,5 & $\pm 1,00$ & 6,6 & $\pm 0,93$ & \multirow{2}{*}{$0,000^{*}$} \\
\hline $\begin{array}{l}\text { Sesudah tes } \\
\text { Hari Ke-2 }\end{array}$ & 3,4 & $\pm 0,90$ & 4.8 & $\pm 0,92$ & \\
\hline Sebelum tes & 4,8 & $\pm 1,03$ & 5,4 & $\pm 0,88$ & \multirow{3}{*}{$0,000^{*}$} \\
\hline Sesudah tes & 2 & $\pm 0,65$ & 3,9 & $\pm 0,79$ & \\
\hline Hari Ke-3 & & & & & \\
\hline Sebelum tes & 3,5 & $\pm 1,02$ & 4,3 & $\pm 0,76$ & \multirow{2}{*}{$0,000^{*}$} \\
\hline Sesudah tes & 0,9 & $\pm 0,57$ & 3,0 & $\pm 0,58$ & \\
\hline
\end{tabular}

* Uji Mann Whitney

Berdasar tabel 1 menunjukan rata-rata skala dismenore sebelum dilakukan teknik endorphin massage dengan kompres hangat berada dalam rentang yang sama yaitu pada skala nyeri berat, setelah dilakukan teknik endorphin massage terjadi penurunan skala dismenore menjadi skala nyeri ringan. Sedangkan pada kelompok kompres hangat penurunan skala nyeri yaitu nyeri sedang. Hasil uji mann whitney diperoleh nilai $p=0,000$ lebih kecil dari 0,05 sehingga dapat disimpulkan bahwa terdapat perbedaan bermakna antara teknik endorphin massage dengan kompres hangat terhadap penurunan skala dismenore.

\section{PEMBAHASAN}

Berdasarkan hasil penelitian pada mahasiswi yang mengalami dismenore dalam 3 hari menstruasi penurunan skala dismenore menggunakan teknik endorphin massage dibandingkan dengan kompres hangat di STIKes Muhammadiyah Ciamis menunjukan, bahwa terdapat perbedaan yang signifikan antara teknik endorphin massage dengan teknik kompres hangat. Dari perbedaan tersebut dapat diketahui bahwa teknik endorphin massage lebih cepat dalam menurunkan skala dismenore dibandingkan kompres hangat. Berdasarkan hasil penelitian pada mahasiswi yang mengalami dismenore dalam 3 hari menstruasi penurunan skala dismenore menggunakan teknik endorphin massage dibandingkan dengan kompres hangat di STIKes Muhammadiyah Ciamis hasil uji menunjukan bahwa terdapat perbedaan yang signifikan antara teknik endorphin massage dengan teknik kompres hangat. Dari perbedaan tersebut dapat diketahui bahwa teknik endorphin massage lebih cepat dalam menurunkan skala dismenore dibandingkan kompres hangat. Mahasiswa yang diberikan terapi endorphin massage mengalami perubahan intensitas nyeri karena mekanisme pemijatan atau sentuhan ini menggunakan teori penngendalian gerbang informasi nyeri yang bergantung pada keseimbangan aktifitas di serat saraf berdiameter besar dan kecil disepajang spina columna yang dapat menghambat hantaran nyeri ke otak.

Endorphin massage yaitu suatu metode sentuhaan ringan yang pertama kali dikembangkan oleh, Constance Palinsky digunakan untuk mengelola rasa sakit. Teknik sentuhan ringan juga membantu menormalkan denyut jantung dan tekanan darah. Teknik sentuhan ringan ini mencakup pemijatan ringan yang dapat membuat bulu-bulu halus pada permukaan kulit berdiri. Sejumlah penelitian membuktikan bahwa teknik ini meningkatkan pelepasn hormon endorphin dan oksitosin yang berfungsi untuk mengurangi rasa sakit. (Safitri R. 2015)

Cara kerja endorphin dalam mengurangi rasa nyeri melalui pengeluaran hormon endorphin dapat memblok transmisi stimulus nyeri sehingga menurunkan kecemasan dan nyeri. Sentuhan dan massage, merupakan teknik integrasi sensori yang mempengaruhi aktivitas sistem saraf otonom, sistem saraf desenden bekerja melepaskan neuroregulator yang menghambat transmisi stimulus nyeri. Serabut $A$ Delta akan menutup gerbang sehingga mengakibatkan Cortex Cerebri tidak menerima pesan nyeri karena sudah diblokir oleh Counter stimulasi, sehingga persepsi nyeri akan berubah. (Judha M.2012)

Pada penelitian yeni menyataan bahwa hasil massage pada punggung yang dimulai pada 
servikal (tujuh) 7 ke arah bagian luar menuju sisi tulang rusuk dapat mengaktivasi serabut serabut saraf berdiameter besar untuk menutup pintu gerbang hantaran nyeri yang dibawa oleh serabut berdiameter kecil sehingga tertutupnya hantaran nyeri ke kortek serebral dan mengakibatkan rasannyeri berkurang. (Trimayasari D dan Kuswandi K. 2014)

Dengan ini peneliti menyimpulkan bahwa stimulasi pada kulit dengan teknik massage menghasilkan impuls, yang dikirim lewat serabut saraf besar yang berada di permukaan kulit, serabut saraf besar akan menutup gerbang sehingga otak tidak menerima pesan nyeri karena telah diblokir oleh stimulasi kulit, akibatnya persepsi nyeri akan berubah. Selain meredakan rasa nyeri, teknik ini juga dapat mengurangi ketegangan otot dan meningkatkan sirkulasi darah di area yang terasa nnyeri. Teknik massage ini menimbulkan efek memperlancar peredaran darah, ini berarti suplai darah ke jaringan menjadi lancar, terutama pada jaringan iskemi dimana saat nyeri haid atau dismenore terjadi kontraksi rahim yang dapat menyebabkan iskemi pada daerah kotraksi tersebut. Hipotalamus akan merangsang hipofise anterior untuk menghasilkan endorphin yang dapat menimbulkan perasaan nyaman dan enak. Sehingga dengan massage ini lebih efektif menurukan nyeri. (Field T. 2012)

\section{SIMPULAN}

Simpulan pada penelitian ini adalah pemberian teknik endorphin massage lebih cepat menurunkan dismenore dibanding dengan kompres hangat pada mahasiswi STIKes Muhammadiyah Ciamis, terlihat pada teknik endorphine massage lebih banyak mengalami penurunan pada 5 menit kedua di setiap hari pengukuran.

\section{SARAN}

Hasil penelitian dapat mejadi salah satu bahan kajian atau referensi untuk peneliti lain dalam penelitian-penelitian selanjutnya serta menjadi baham pembelajaran bagi para pembaca terutama tentang endorphin massage sebagai terapi non farmakologi untuk mengatasi dismenore.

\section{DAFTAR PUSTAKA}

Achmad S. Roswendi. Pengaruh hipnoterapi terhadap nyeri haid (dismenore) pada mahasiswa DIII Kebidanan stikes a.yani cimahi. Bandung . J Kesehatan Kartika. 2015.10(2).

Anugraheni $V$ dan Wahyuningsih $A$. Efektifitas kompres hangat dalam menurunkan intensitas nyeri dysmenorrhoea. J STIKES Baptis. Kediri.2013: 6(1)

Aprilia. Teknik massage endorphine. Jakarta : Penerbit Gagas Media; 2010.

Arifin S. Nyeri haid. Jakarta; EGC; 2008

Arikunto. Prosedur penelitian suatu pendekatan praktik. Jakarta: Rineka Cipta; 2009.

Aryani y, masrul dan evareny L. Pengaruh Masase pada punggung terhadap intensitas nyeri kala I fase laten persalinan normal melalui peningkatan kadar endorphin. Padang; J Kes Andalas; 2015; 4(1)

Aulia. Kupas tuntas menstruasi. Yogyakarta Milestone; 2009.

Dahlan MS. Statistik kesehatan untuk kedokteran dan kesehatan: deskriptif, bivariat, dan multivariat. Jakarta: Epidemiologi Indonesia; 2016.

Deswita. Psikologi perkembangan remaja. Bandung: Rosdakarya; 2009

Field T. Massage therapy. Med Clin Norrth Am. 2012;86:163-71

Handayani Y E dan Rahayu L S. Faktor-faktor yang Berhubungan dengan Nyeri Menstruasi (Dismenorea) pada Remaja Putri di Beberapa SMA di Kabupaten Rokan Hulu. Rokan Hulu : J Maternity and Neonatal.2014;1(4)

Hartati W Esti. Pengaruh teknik relaksasi front effleurage terhadap nyeri Dismenore. Semarang : J Riset Kesehatan ; 2015. 4(3)

Hendrik. Problema haid. Solo:Tiga serangkai; 2006

Judha M. Teori pengukuran nyeri dan nyeri persalinan. Yogyakarta : Nuha Medika; 2012.

Kasumayanti E. Faktor-faktor yang Berhubungan dengan Kejadian Disminore di SMAN 5 Pekanbaru. Riau : J Keperawatan STIKes Tuanku Tambusai.2015.

Kuswandi lanny. Kehamilan dan persalinan dengan hypnobrithing. Jakarta PT : Bhuana ilmu populer kelompok gramedia; 2013.

Laila N N. Buku pintar menstruasi. Yogyakarta : Bukubiru; 2011.

M. Sopiyudin, D. Membaca dan menelaah jurnal uji klinis. Jakarta: Salemba Medika;2010.

Marlinda, R. Purwaningsih. Pengaruh senam disminore terhadap penurunan disminore pada remaja putri di desa sidoarjo kecamatan pati. Semarang : J Keperawatan Maternitas;2013.1(2):118-123

Marmi. Gizi dalam kesehatan reproduksi. Yogyakarta :Pustaka Pelajar: 2013

Ningsih R. Efektivitas paket pereda nyeri pada remaja dengan dismenore. Bengkulu : J Kep Ind.2013 16(2);67-76. 


\section{JKM (Jurnal Kebidanan Malahayati),Vol 7,No.2.April 2021, \\ ISSN (Print) 2476-8944 ISSN (Online) 2579-762X, Hal 319-323}

Novia I, Puspitasari N. Faktor risiko yang mempengaruhi kejadian dismenore primer. The Indonesia $\mathrm{J}$ of Public Healt. 2008;4(2):96-104

Potter PA, Perry AG. Buku ajar fundamental keperawatan. Edisi ke-7, buku ketiga, Jakarta; EGC;2010

Prawirohardjo, S.IImu kebidanan. Jakarta: PT Bina Pustaka Sarwono Prawirohardjo:2011

Priscilla V, Dwi dan Lili. Perbedaan pengaruh teknik relaksasi nafas dalam dan kompres hangat dalam menurunkan dismenore pada remaja sma negeri 3 padang. Padang : Ners J Keperawatan;2012.8(2):187-195.

Proverawati, A \& Misaroh S. Menarche : Menstruasi pertama penuh makna. Yogyakarta: Nuha Medika; 2009.

Rahayu A. Pengaruh endorphine massage terhadap rasa sakit dismenore pada mahaiswa jurusan kebidanan Poltekkes Kemenkes Tasikmalaya : J Bidan "midwife journal" :2017: 3(2).

Rahmadhayanti E. Pengaruh kompres hangat terhadap penurunan derajat nyeri haid remaja putri di SMA Karya Ibu Palembang. Palembang : J Kesehatan. 2017:8(3) :369374

Safitri R. Gambaran Skala Nyeri Haid Pada Usia Remaja, Bandung : Jurnal Keperawatan STIKes Aisyiyah Bandung; 2015. Hal : 25-9.
Saguni F C A S, Madianung A, dan Masi G. Hubungan Dismenore dengan Aktivitas Belajar Remaja Putri di SMA Kristen 1 Tomohon. Manado : ejournal keperawatan (e-Kp) Volume 1, No. 1; 2013.

Saguni F C A S, Madianung A, dan Masi G. Hubungan Dismenore dengan Aktivitas Belajar Remaja Putri di SMA Kristen 1 Tomohon. Manado : ejournal keperawatan (e-Kp).2013: 1(1).

Sarwono S. Psikologi remaja. Jakarta: PT Raja Grafindo :2011

Supriatin E. Hubungan kecemasan remaja dengan kejadian dismenorea pada siswi SMP $X$ Bandung. Bandung : J IImu Keperawatan.2014;11(1).

Trimayasari $\mathrm{D}$ dan Kuswandi K. Hubungan usia menarche dan status gizi siswa smp kelas 2 dengan kejadian dismenore. Banten : J Obstretika Scientia.2014; ( 2 ) 2.

Utari D M. Pengaruh pemberian ramuan jahe terhadap nyeri haid mahasiswi STIKES PMC Tahun 2015. Pekanbaru : J IPTEKS Terapan Research of Applied Science and Education; 2015.11(3): $257-264$.

Varney H. Kriebs MJ., Gegor CL. Buku ajar asuhan kebidanan. $4^{\text {th }}$ ed. Jakarta : EGC; 2008.

Wiknjosastro, H. IImu kebidanan. Jakarta: Yayasan Bina Pustaka Sarwono Prawirohardjo; 2009. 